\title{
Start and goal speeds as functions of runway length'
}

THOMAS CLIFFORD AND CASPER CROUSE, ${ }^{2}$ DEPARTMENT OF PSYCHOLOGY, KENYON COLLEGE, Gambier, Ohio 43022

More pronounced effects of runway length were found in the goal box than in the start box, an $8 \mathrm{ft}$ runway producing slower speeds than a 2 ft runway or a $4 \mathrm{ft}$ runway.

Psychological theories generally assume that motivation for an incentive increases with proximity to the incentive (cf. Atkinson, 1964). As they also generally assume a direct relation between motivation and performance, an observation by Hull (1934) seems contrary. He found that the approach gradient in the early stages of training in a $20-\mathrm{ft}$ runway had the appearance of "a foreshortened gradient from a 40-foot runway, rather than the posterior half of a 40 -foot gradient which should be the case if the goal excitatory gradient alone were operative [p. 419]." As a further examination of the relations between goal proximity, incentive motivation, and performance, starting speeds and goal speeds were measured in runways of three lengths, $2 \mathrm{ft}, 4 \mathrm{ft}$, and 8 ft.

Subjects. Twenty-four male and 24 female hooded rats, from 150 to 300 days old at the beginning of training were divided equally, balancing for sex and age, into three groups, one for each runway length. Males were run in the morning, females in the afternoon; the apparatus was washed and sprayed with Glade disinfectant and deodorant after each half-day session.

Apparatus. A runway, with start section and goal section, was built of $3 / 4$ in. plywood and painted flat black. It was 4 in. wide and 6 in. high with hinged $1 / 4$ in. hardware cloth tops over all sections. The start section was 29 in. long with a spring-loaded, black masonite door opening laterally to the right 11 in. from the end. The goal section was $293 / 4$-in. long with a manually operated similar door $15 \mathrm{in}$. from the entry. The last $4 \%$-in. of the goal section was 2 in. wider, recessed to the right. A sheet aluminum clip, 3 in. wide and $5 \mathrm{in}$. long with a lip extending out $1 / 2$-in. at the bottom, fitted into the recess and held, on the lip at the bottom, a $1 / 4-t s p$ aluminum measuring spoon for the reward. Two center runway sections, $2 \mathrm{ft}$ long and $6 \mathrm{ft}$ long, were built to fit between the start and goal sections to make the apparatus longer. The sections connected with hooks and had notched $1 / 2$ in. overlaps at the joints. The three setups are referred to as the 2-ft runway, the 4-ft runway, and the 8 -ft runway.

Starting times and goal times were measured with .01-sec Lafayette clocks controlled by a switch on the starting door and photobeams projected across the runway. Starting time was measured from open-door to break-beam 1, 6 in. beyond the door; goal time was measured between beams across a $1 \mathrm{ft}$ interval that terminated 1 in. before the goal recess.

The photobeams, from $6 \mathrm{~V}$, No. 47 bulbs mounted on the outside walls, passed through $7 / 8 \mathrm{in}$. holes centered $13 / 4$-in. above the floor. Filters of four layers of red cellophane and three layers of green cellophane were mounted between the bulbs and the holes. The holes were sealed with clear plastic discs mounted flush with the inside walls. The beams were received, on the opposite side of the runway, by light-sealed photocells with associated relays. Switching circuits between photocells and clocks were accomplished through $24 \mathrm{~V}$ telephone relays. Apparatus sounds and extraneous noise were masked with classical music at a comfortable level programmed over WRFD-FM. The noise of relays switching was not a significant distraction. The $50 \%$ sucrose solution used for rewards was prepared every two or three days by mixing equal amounts of table sugar and tap water. Each reward of two drops was measured with an eye dropper.

Procedure. A deprivation schedule of $1 \frac{1 / 2}{h}$ of feeding daily was begun at least one week before the first pretraining day. Ss were run five days per week during the $31 / 2 \mathrm{~h}$ period just prior to feeding on each day.

Pretraining lasted for five days and was a continuation of gentling plus adaptation to the start box and goal situations. On Day $1, \mathrm{~S}$ was placed in a pretraining box and left to drink two drops of $50 \%$ sucrose solution from the spoon. The pretraining box was an 8-in. square black box of plywood with 6 in. high walls and a $1 / 4$ in. hardware cloth top. This was followed by two placements into the start box where the start box door was opened after $S$ had oriented toward it. A plug in the runway prevented S's advancing. Days 2 and 3 were the same as Day 1 except that two reward exposures were given instead of one. Days 4 and 5 were the same as 2 and 3 except that the closed goal box was substituted for the pretraining box.
Acquisition training was continued for 60 trials at a rate of six trials per day except for the first four days when one, one, two, and two trials, respectively, were given each day. The intertrial interval was always at least 5 min. On each trial, $\mathrm{S}$ was removed from its individual cage, placed into the closed start box from the top, released by the spring-loaded door after approximately $4 \mathrm{sec}$, and allowed to run to the goal box. The retrace door in the goal box was closed after the last photobeam was broken. The spoon was loaded on each trial with a reward of two drops of $50 \%$ sucrose solution. $S$ was removed to its home cage immediately after drinking.

Results and Discussion. Median times were obtained for the last five of each block of six trials and converted to speeds in $\mathrm{ft} / \mathrm{sec}$. Figure 1 depicts the average speeds for each runway length across trial blocks. For the start box data, an overall analysis of variance showed a nonsignificant length effect $(F=1.79$, df $=2 / 45)$, a significant trial blocks effect $(F=65.97, \mathrm{df}=9 / 405, \mathrm{p}<.01)$, and a nonsignificant interaction $(F<1)$. These findings are essentially unimpressive. They suggest either that the data are unreliable or that starting speeds vary but slightly with distance to the incentive in this situation. Given the possibilities for generalization in the relatively homogeneous runway, the latter conclusion is reasonable. It is possible that performance differences would have appeared had the differences between lengths been more extreme. Besch \& Reynolds (1958), also using black runways, reported greater starting speeds for a $4 \mathrm{ft}$ runway than for a $16 \mathrm{ft}$ runway. In the present study, the lengths effect was significant in a separate analysis for terminal acquisition data $(F=4.04$, df $=$ $2 / 45, \mathrm{p}<.05$ ) as were $\mathrm{t}$ tests within that analysis (Hays, 1963, Ch. 14). In pair-wise tests, 2 vs 4 and 4 vs 8 were nonsignificant, but 2 vs 8 was significant $(\mathrm{p}<.01)$; a test of 2 vs 4 and 8 and a test of 2 and 4 vs 8 were also significant ( $p<.02$ for each), but of course not independently of the pair-wise tests.

Goal box data present a different picture. In the overall analysis, effects for lengths $(F=3.20, \mathrm{df}=2 / 45, \mathrm{p}<.05)$, trial blocks $(F=59.33, \mathrm{df}=9 / 405, p<.01)$, and lengths by trial blocks interaction $(F=2.55, \mathrm{df}=18 / 405, \mathrm{p}<.01)$ were all significant. So, too was the length effect in the terminal acquisition analysis $(F=6.07, \mathrm{df}=2 / 45, \mathrm{p}<.01)$. The $t$ test for terminal acquisition 2 and 4 vs 8 was significant $(p<.01)$. The same comparison was made across each trial block separately using a confidence interval based on the error term for length from the overall analysis. It was significant with $\mathrm{p}<.05$ for every block beyond the third. One may conclude that except for a brief initial stage of training, rats running from $8 \mathrm{ft}$ away entered the goal box significantly slower than rats running from either $2 \mathrm{ft}$ away or $4 \mathrm{ft}$ away. Hull's (1934) data indicates an opposite difference; speeds nearest the goal were slightly, though probably not significantly, faster in a $40-\mathrm{ft}$ runway than in a $20-\mathrm{ft}$ runway. There seems to be no other directly relevant data available for comparison. For the present, one may at least conclude that the relations between goal proximity, incentive motivation, and performance in a straight runway are not simple.

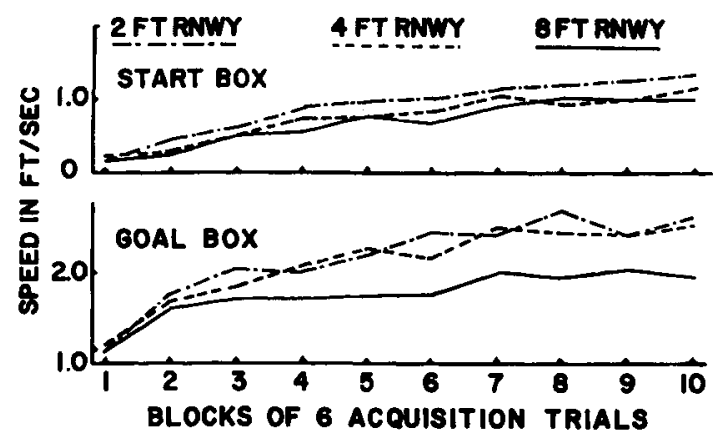

Fig. 1. Starting speeds and goal speeds over blocks of acquisition trials. 


\section{REFERENCES}

ATKINSON, J. W. An introduction to motivation. Princeton: Van Nostrand, 1964.

BESCH, N. F., \& REYNOLDS, W. F. Alley length and time of food deprivation in instrumental learning. $J$. exp. Psychol., 1958, 56, 448-452.

HAYS, W. L. Statistics for psychologists. New York: Holt, Rinehart and Winston, 1963.

HULL, C. L. The rat's speed of locomotion gradient in the approach to food.
J. comp. Psychol, 1934, 17, 393-422.

NOTES

1. This research was sponsored by NSF Grant GB 2858 and the Kenyon College Research Fund. The assistance of Dr. Roy Reeves, Director of the Computer Center of The Ohio State University, and Mr. Thomas Ritter, of the Cooper-Bessemer Corporation of Mount Vernon, Ohio, in providing facilities for data analysis is gratefully acknowledged.

2. Now at Harvard University. 